\title{
Public engagement with photonics: International Year of Light celebratory event in Wales
}

Ray Davies, K. Alan Shore

Ray Davies, K. Alan Shore, "Public engagement with photonics: International Year of Light celebratory event in Wales," Proc. SPIE 9793, Education and Training in Optics and Photonics: ETOP 2015, 97932 S (8 October 2015); doi: $10.1117 / 12.2223236$

SPIE Event: Education and Training in Optics and Photonics: ETOP 2015, 2015, Bordeaux, France 


\title{
Public Engagement with Photonics: International Year of Light Celebratory Event in Wales
}

\author{
Ray Davies and K Alan Shore \\ Photonics Academy of Wales @ Bangor (PAWB) \\ Bangor University, School of Electronic Engineering, \\ Dean Street, BANGOR LL57 1UT \\ Wales, UK
}

\begin{abstract}
In arranging events in Wales to celebrate the International Year of Light emphasis has been placed on activities which allow the participation of the broadest possible cross-section of the public. This paper will offer a summary of events undertaken and a perspective on those planned for the remainder of the year. Plans for legacy activities will also be outlined.
\end{abstract}

Keywords : photonics; education and training ; outreach;

\section{Introduction}

Following the declaration by the UN on 20 December 2013, based on a proposal made by the European Physical Society that 2015 should be the International Year of Light (IYOL), the Photonics Academy for Wales at Bangor (PAWB) undertook to organise a series of events in Wales in support of the IYOL. PAWB prepared a document outlining a plan for activities in Wales to celebrate the IYOL but simultaneously sought expressions of interest from those who would be ready to organise or participate in such events. The initially declared aimed was to provide a variety of public events which will demonstrate the importance of light in supporting and enhancing life. It was indicated that such events would occur on a pan-Wales bilingual basis and should engage people in a range of settings. A particular emphasis will be on giving the general public 'hands-on 'opportunities to appreciate the role which light plays in daily life.

The expectation was that several key organisations would coordinate their activities in order to facilitate such events. To this end, initial approaches were made to: the Institute of Physics in Wales ; The Photonics Academy of Wales, the Welsh Optoelectronics Forum and the Learned Society of Wales. A hope was expressed that other organisations which have light-related activities will also be ready to join in these activities. Here opportunities are seen in areas from astronomy to solar power generation ; from biology to ophthalmology; from communications to laser manufacturing.

In addition to engagement by a variety of organisations, it was envisaged that input into activities could arise from institutions and agencies including educational establishments and government bodies such as the office of the Chief Scientist for Wales. Given the significant role which light plays in the economy of Wales it was also expected that industrial and commercial bodies will be ready to support and participate in 'International Year of Light : Wales'.

\section{Supportive Organisations}

Having sought engagement from a variety of organisations it is gratifying to report a positive response from several quarters - some of which were unforeseen. Rather than attempt to arrange those responses in any kind of order of importance the simplest and most direct way for indicating how such a response emerged is to present those contributions roughly in chronological order.

Education and Training in Optics and Photonics: ETOP 2015, edited by Eric Cormier, Laurent Sarger Proc. of SPIE Vol. 9793, 97932S · (C) 2015 SPIE, IEEE, OSA, ICO · doi: 10.1117/12.2223236 


\section{THE LEARNED SOCIETY OF WALES CYMDEITHAS DDYSGEDIG CYMRU}

CELERARTING SCHOLARSHIP AND SERVING THE NATION

The first organisation which responded in a practical way was the Learned Society of Wales. The Learned Society of Wales (LSW) (http://learnedsocietywales.ac.uk/) is an independent, all-Wales, selfgoverning, pan-discipline educational charity, providing public benefit including expert scholarly advice on a variety of public policy issues related to science, engineering, medicine, arts, humanities and social sciences. Established in 2010, the Society draws upon the considerable strengths of over 350 distinguished Fellows based in Wales, the UK and beyond. The Society, Wales's first national scholarly academy, aims to establish itself both as a recognised international representative of the world of Welsh learning, and as a source of authoritative, scholarly, and critical comment and advice on policy issues affecting Wales.

One of the present authors (KAS) is a member of the Council of the LSW and when he presented a short paper to the LSW Council the then Chief Executive of the LSW Dr Lynn Williams immediately made an offer of sponsoring a Christmas Lecture for Schools on the topic "Chemistry and Light '. This was delivered in Bangor - and the seats could have been filled twice over. It is stressed that this was Christmas 2014 and so IYoL in Wales got off to an early start and, literally with a bang.

\section{Eisteddfod}

A major cultural event in Wales is the National Eisteddfod of Wales. This week-long annual peripatetic event draws in excess of 250,000 people of all ages to locations across Wales( http://www.eisteddfod.org.uk/english/2015/). In 2015 the National Eisteddfod will be held in Meifod, mid Wales. In recent years the LSW has sponsored an annual lecture at the National Eisteddfod and in 2015 the LSW has also offered its annual National Eisteddfod lecture as part of the IYOL activities.This lecture will be delivered ( in Welsh ) by one of the present authors (KAS).

The second organisation which enthusiastically embraced the IYOL was the Welsh Optoelectronics Forum (http://www.wof.org.uk/home/). The Forum is a consortium of Welsh companies, University research groups, users and support organisations, formed following the impetus of activities in north Wales, and is dedicated to the development and profitability of the opto-electronics sector in Wales and internationally. Opto-electronics is all around and part of everyone's daily life, and probably those who will gain most from the Forum are the people and companies for whom the technology currently forms a small part of their work. Alongside the several anniversaries which underpin the choice of 2015 as the IYOL, it happens that 2015 marks 20 years of activity by the Welsh Optoelectronics Forum (WOF) .

2015 also is the $10^{\text {th }}$ anniversary of the establishment by WOF of the Photonics Academy for Wales. It is natural therefore that both these organisations will contribute to IYOL events.
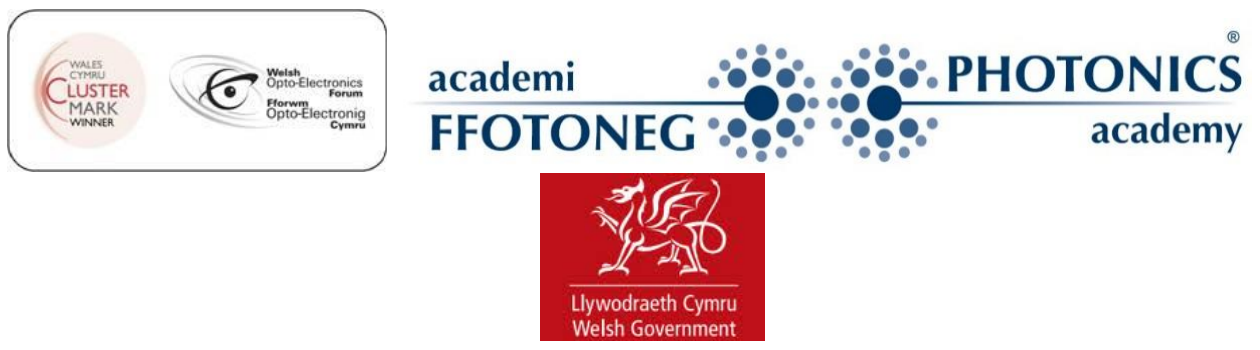

An approach was made to the Chief Scientific adviser for Wales (CSAW) Professor Julie Williams for both moral and financial support for IYOL events and specifically for the formal launch of the IYOL in Wales which is described in more detail below. One records with great appreciation the support thereby forthcoming. 
One may say that many of the foregoing organisations would have been fully expected to join IYOL activities. It is pleasing to record that support has come from rather unexpected directions.

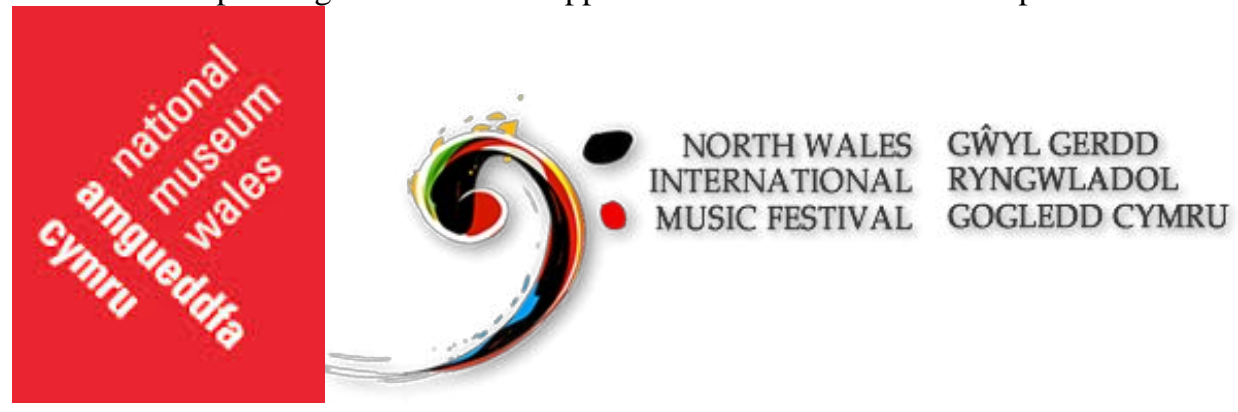

The National Museum of Wales( http://www.museumwales.ac.uk/) - and in particular Dr Jana Horak has embraced the IYOL with considerable imagination and energy. Dr Horak has organised a number of events under the title 'Geology and Light ' in the period June-August 2015.

The North Wales International Music Festival http://nwimf.com/home/index.html .- led by Anne Atkinson - has adopted light as the motif for its events in September/ October (In 2014 its theme was literature - related to the centenary of the birth of the poet Dylan Thomas.) It happens that there has historically been a strong link between the Welsh Optoelectronics Forum and the North Wales Music Festival. However WOF cannot claim any credit for the decision by Anne Atkinson to adopt light as a theme for the 2015 North Wales Music Festival. It appears that Anne Atkinson picked up early indications of the IYOL and decided to use it for the festival.

At this time work is still in progress to engage other "non-traditional ' science events in the IYoL. It is hoped that a "light artist ' will be involved with 'Pontio 'a major 'Arts and Innovation ' centre being completed at Bangor University. A centre for sailing under construction in Pwllheli, north Wales aims to include photonics exhibits as part of its on-going activities.

But it is important also to mention some 'usual suspects ' who will support the IYOL in Wales . The SIOE conference in Cardiff organised by Peter Smowton will be part of our activities. Glyndwr University will be presenting a lecture on Maxwell's Equations by Peter Excell and other events at OpTIC Glyndwr. Aberystwyth Physics under the leadership of Andy Evans will also contribute. It is expected that several photonics companies in Wales will involve themselves in IYOL activities.

\section{Programme of Events}

PAWB has worked with several organisations and individuals to devise a programme of events which are focussed on conveying the significance of light and its technologies to a broad swathe of the population. The target was to have an event per month somewhere in Wales These events take into account the bi-lingual nature of Wales with significant events being delivered in the Welsh language. Arrangement and delivery of the events has largely been undertaken on a voluntary basis albeit with some funding having been obtained from supportive bodies and organisations.

\section{IYOL Wales Events Calendar}

The following are events in which PAWB has been /will be active or of which it is aware

\subsection{PAWB Activities}

December 2014 LSW School Lecture 'Chemistry and Light'. '

$20^{\text {th }} / 21^{\text {st }}$ January IYOL Launch Paris

$5^{\text {th }}$ February IYOL Launch Wales, Cardiff 
$31^{\text {st }}$ March-2 $2^{\text {nd }}$ April SIOE Conference Cardiff

$16^{\text {th }}-18^{\text {th }}$ February Photonics Project Master Class -8 students from Friars School, Bangor

4th March OpenIQE Photonics Innovation Camp - OpTIC : PAWB Display

$14^{\text {th }}$ March Hidden Worlds Exhibition - Brambell Building (Bangor Science Festival)

$25^{\text {th }}$ March EESW Project Presentation Day at Venue Cymru,Llandudno Projects : Roof Prism

Optical Compass; Fibre Optic Laser Speckle Cardiopulmonary Resuscitation (CPR);Blind Person's

Stair Ascending/Descending Sensor

$21^{\text {st }}$ April “Surprised by Light" - Phoenix Society - Kidderminster

$20^{\text {th }}$ June $/ 25^{\text {th }}$ July/ $15^{\text {th }}$ August Geology and Light : National Museum of Wales, Cardiff

$5^{\text {th }}-10^{\text {th }}$ July Desborough College Photonics Course

July-August PAWB Summer School

July-December : National Research Network in Advanced Engineering sponsored public lectures on photonics technologies

$1^{\text {st }}-8^{\text {th }}$ August National Eisteddfod of Wales (Meifod) : Learned Society of Wales Annual Eisteddfod Lecture

$25^{\text {th }}$ September Lightfest @ Aston University,Birmingham

October-December PAWB Magical Home

November 2015 Bangor University Annual Engineering Public Lecture : Sir Michael Berry, Bristol University

Other events

February $20^{\text {th }}$ Maxwell's Equations, Peter Excel,Glyndwr University Denbigh

June STFC Road Show Cardiff

September/October North Wales Music Festival

In respect of events which have been completed by the time of the ETOP conference an attempt will be made to evaluate the effectiveness of the approach adopted and also to consider how that evaluation may inform forthcoming events.

\subsection{IYOL Wales Launch}

It is wished to draw particular attention to the IYOL Wales Launch. The event took place on the $5^{\text {th }}$ February in the Pierhead Building, which is adjacent to the Welsh Senedd - the home of the Welsh Assembly in Cardiff Bay. The event was formally sponsored by Mrs Edwina Hart Welsh Government Minister for the Economy,Science and Transport. The Wales Launch of the International Year of Light was attended by representatives of a broad cross section of companies and organisations which have an interest in photonics. The launch event was addressed by Mrs Hart, Professor Julie Williams, Chief Scientific Adviser for Wales ; Karin Burger of SPIE Europe ; Dr Louise Jones of the Knowledge Transfer Network and Dr Beth Taylor of the Institute of Physics who chairs the UK organising committee for the IYOL. The event was chaired by Prof Alan Shore of PAWB. The event also included displays and exhibits by photonics companies and supporting organisations. The Learned Society of 
Wales, who exhibited at the event, also supported the costs of Simon Gough Photography who provided several of the following images.

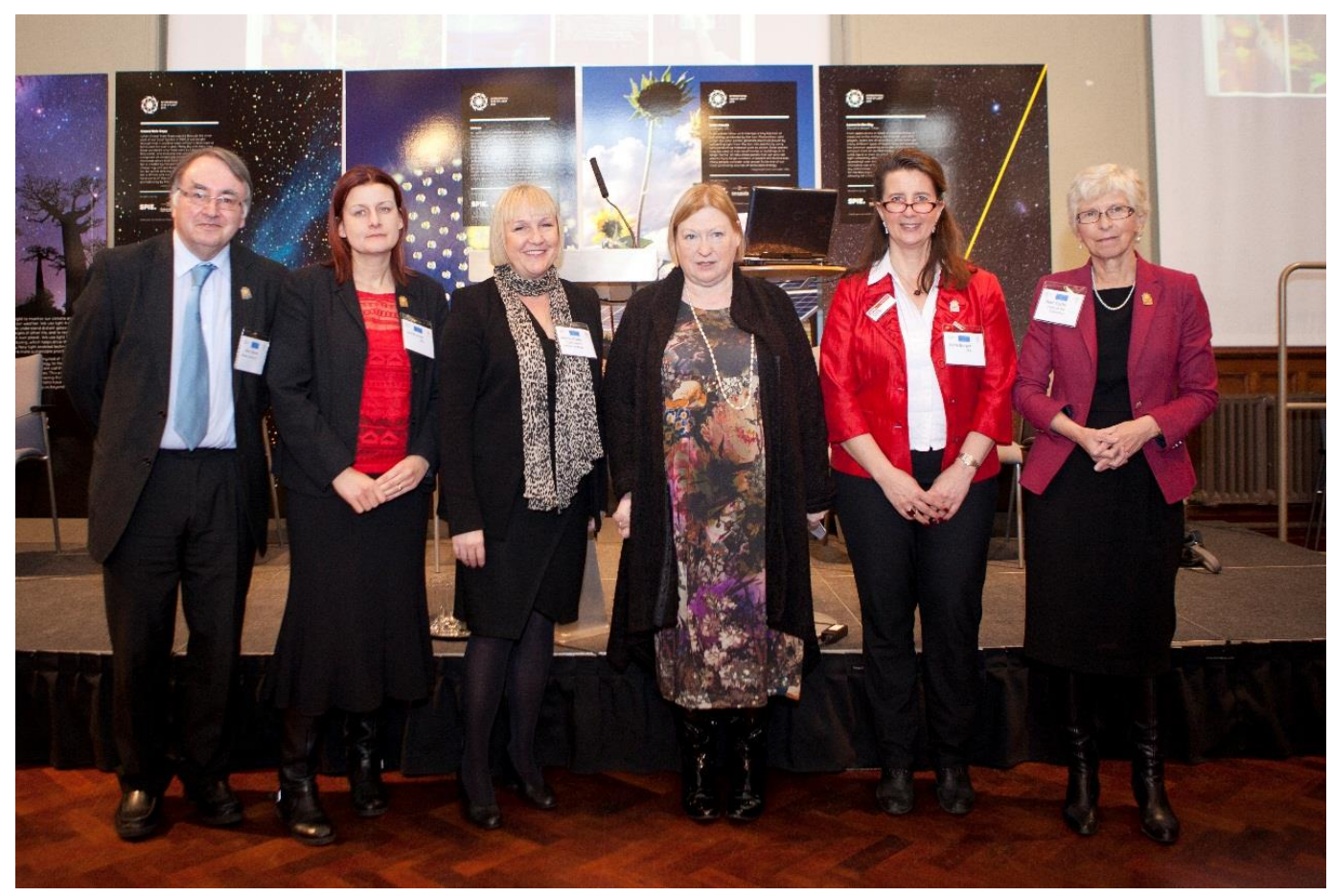

Speakers at the Wales Launch of the IYOL,Cardiff, February 2015 from left to right :

KAS ; Dr Louise Jones ; Professor Julie Williams,

Mrs Edwina Hart, Karin Berger and Dr Beth Taylor

Learned Society of Wales /Simon Gough Photography

Karin Berger contributed very generously of her time in organising the event and notably for ensuring that all the logistics associated with the exhibits were efficiently undertaken. SPIE also provided the background displays used at the launch.Thanks are due to Dr Zubaida Sattar and Daniel Roberts for bringing some examples of Photonics Academy of wales @ Bangor (PAWB) activity to the IYOL Wales launch. Dr Sattar is a Ser Cymru Advanced Engineering NRN post doctoral researcher ; Dan is a PhD student supported by y Coleg Cymraeg Cenedlaethol. Unfortunately Ray Davies who is the motive force behind PAWB was indisposed at the time of the event.

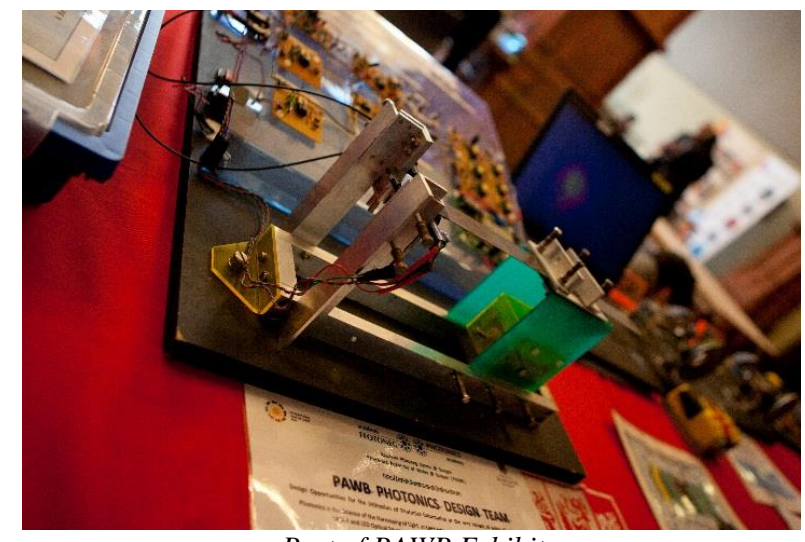

Part of PAWB Exhibit

Learned Society of Wales /Simon Gough Photography 


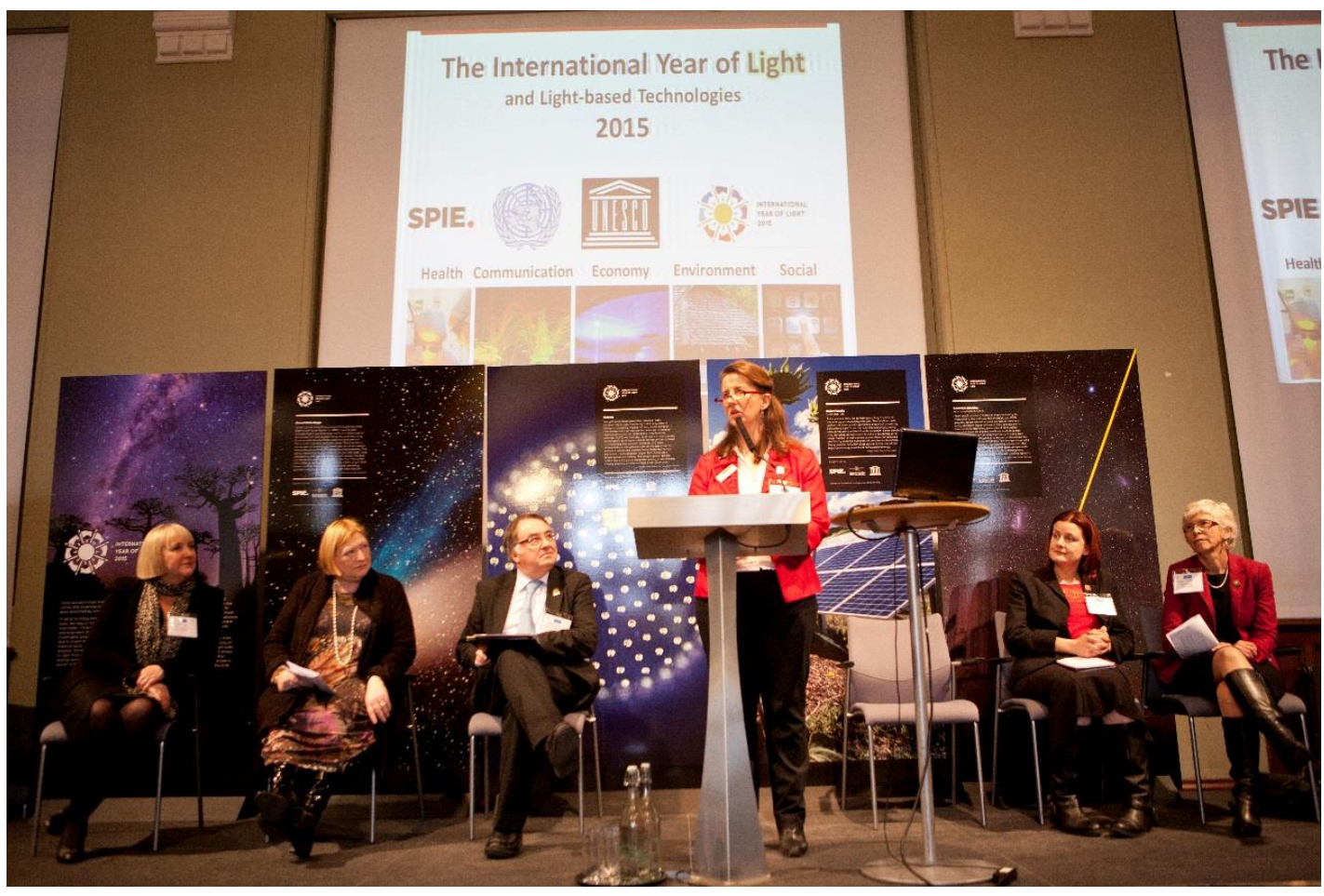

Karin Berger speaking at the IYOL Wales Launch

Learned Society of Wales /Simon Gough Photography

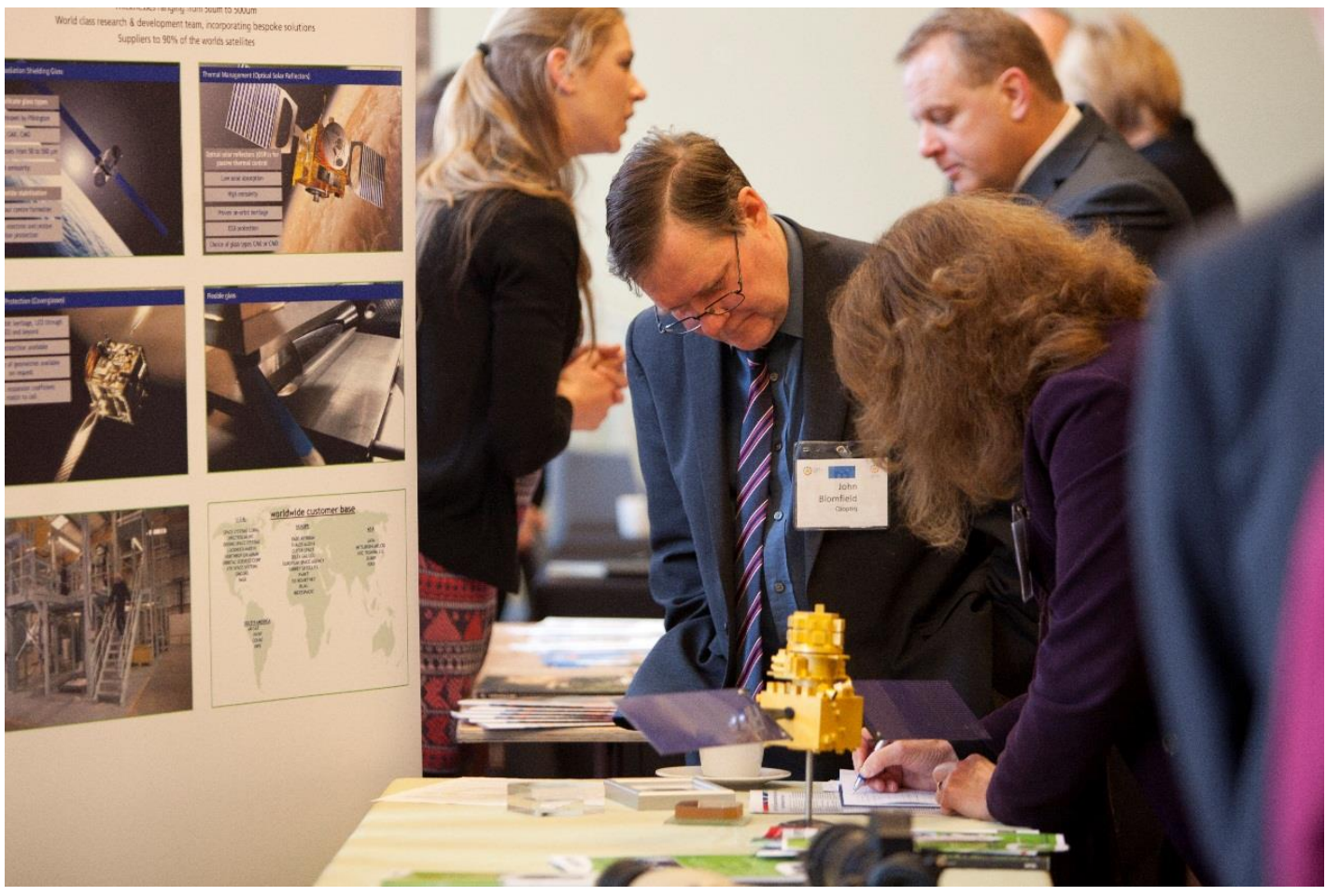

Attendees at a company display

Learned Society of Wales /Simon Gough Photography

Proc. of SPIE Vol. 9793 97932S-6 


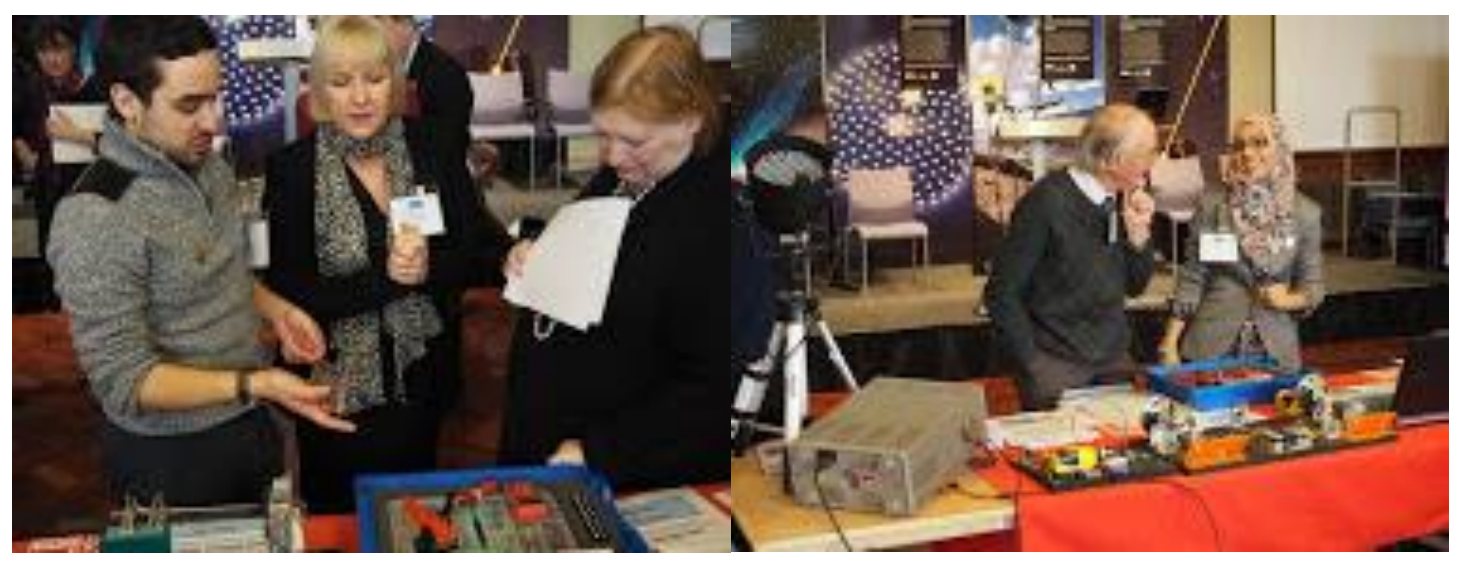

Visitors at the Photonics Academy of Wales @ Bangor (PAWB) display being enlightened by (left) Daniel Roberts and (right) Zubaida Sattar

Images from Toby Shannon,IoP

\section{Legacy}

Being aware of the importance of creating an on-going interest in the topics treated during the International Year of Light, attention is being given to legacy activities beyond 2015.It is palpably premature to consider this aspect in detail whilst IYOL events in Wales and world-wide are underway. At this stage it is perhaps sufficient to indicate briefly that PAWB has the ambition to establish a Photonics Design Challenge as a means for engaging young people in hands-on photonics. The mechanism for implementing that challenge is under active consideration.

In order to conclude one returns to the beginning and the global launch of the IYOL in Paris. The IYOL was in great measure the idea of the European Physical Society president Professor John Dudley. It is worth therefore recalling remarks made by John in relation to the global launch in Paris :

"The world today faces many challenges and it is essential to seize this opportunity to enhance global awareness of the problem-solving potential of photonics in areas such as sustainable development, agriculture, renewable energy and health.

As light becomes a key cross-cutting discipline of science and engineering in the $21^{\text {st }}$ century it is more important than ever to build world-wide educational capacity through activities targeted on science for young people, by addressing issues of gender balance in science and to focus especially on promoting education in developing countries and emerging economies.

We will have only one International Year of Light and it is up to us to make the most of it. "

It is to be greatly hoped that by the end of 2015 the ETOP community will have made its contribution to furthering those aims.

Acknowledgement : KAS gratefully acknowledges the financial support provided by the Sêr Cymru National Research Network in Advanced Engineering and Materials. 